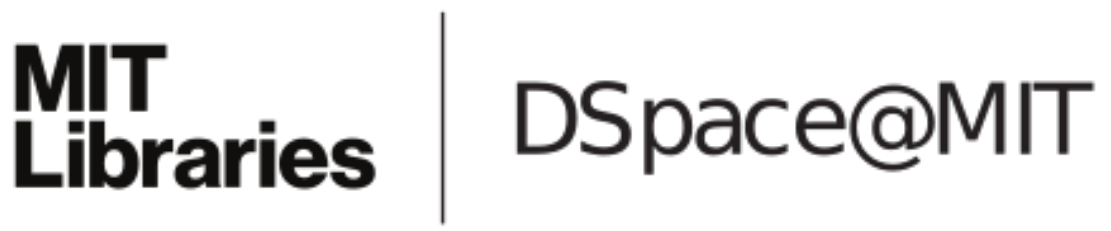

\author{
MIT Open Access Articles
}

\section{Hemodynamic consequences of a multilayer flow modulator in aortic dissection}

The MIT Faculty has made this article openly available. Please share how this access benefits you. Your story matters.

As Published: https://doi.org/10.1007/s11517-019-01997-w

Publisher: Springer Berlin Heidelberg

Persistent URL: https://hdl.handle.net/1721.1/131383

Version: Author's final manuscript: final author's manuscript post peer review, without publisher's formatting or copy editing

Terms of use: Creative Commons Attribution-Noncommercial-Share Alike 


\section{AUTHOR ACCEPTED MANUSCRIPT}

\section{Hemodynamic consequences of a multilayer flow modulator in Aortic Dissection}

Cite this article as: Lambros S. Athanasiou, Farhad Rikhtegar Nezami, and Elazer R. Edelman, Hemodynamic consequences of a multilayer flow modulator in Aortic Dissection, Medical \&amp; Biological Engineering \&amp; Computing, doi: 10.1007/s11517-019-01997-w

This Author Accepted Manuscript is a PDF file of a an unedited peer-reviewed manuscript that has been accepted for publication but has not been copyedited or corrected. The official version of record that is published in the journal is kept up to date and so may therefore differ from this version.

Terms of use and reuse: academic research for non-commercial purposes, see here for full terms.

http://www.springer.com/gb/open-access/authors-rights/aam-terms-v1 


\section{AUTHOR A CCEPTED MANUSCRIPI}

Hemodynamic consequences of a multilayer flow modulator in Aortic Dissection

Lambros S. Athanasiou ${ }^{1,2^{*}+}$, Farhad Rikhtegar Nezami ${ }^{1+}$, and Elazer R. Edelman ${ }^{1,2}$

${ }^{1}$ Institute for Medical Engineering and Science, Massachusetts Institute of Technology, Cambridge, MA, United States

${ }^{2}$ Cardiovascular Division, Brigham and Women's Hospital, Harvard Medical School, Boston, MA, United States

*Corresponding author: e-mail: lambros@mit.edu

${ }^{+}$Contributed equally to the study

Manuscript number of words: 4651

Abstract number of words: 185

Number of figures: 10

Number of tables: 2

(C) 2019 International Federation for Medical and Biological Engineering 


\section{Abstract}

\section{AUTHOR ACCEPTED MANUSCRIPT}

Aortic dissections are challenging for it remains perplexing to determine when surgical, endovascular or medical therapies are optimal. We studied the effect of the multilayer flow modulator (MFM) device in patients with different forms of type-B aortic dissections. CT scans were performed pre, immediately post MFM implantation, and multiple times within a 24-months follow-up. Three-dimensional reconstructions were created from these scans and the multilayer or single-layer mesh device placed virtually into the true lumen.

We observed that MFM device can sufficiently restore flow perfusion, reduce the false lumen, eliminate local flow recirculation, and reduce wall shear stress distribution globally. Single-layer devices can reduce false lumen dimensions, however they generate local disturbance and recirculation zones in selected areas at specific time-points. Moreover, in polar extremes of dissection, the MFM device restored flow to vital organs perfusing vessels independent of effects on luminal patency.

Management of aortic dissections should focus on modulation of blood flow, suppression of local recirculation, and restoration of vital organ perfusion rather than primarily restoring vascular lumen morphology. While the latter restores the geometry of the true lumen only the former restores homeostasis.

Keywords: Aortic dissection, Multilayer Flow Modulator, recirculation, wall shear stress, blood flow. 


\section{Introduction}

Aortic dissections are significant and growing conditions in which the layers of aortic wall separate and tear apart, allowing blood to track within fascial planes which are normally apposed [1]. Hemodynamic forces lead to tear initiation and propagation, splitting the media layer and creating two lumina rather than one for blood access: true lumen and false lumen. The true lumen is the anatomophysiologic aortic lumen that supplies blood to body and vital organs. As blood is directed to false lumen, organ perfusion is reduced and its dilation can compress the true lumen diameter, further reducing forward flow to vital organs. The volume of the false lumen can determine the severity of disease and is a determinant factor for mortality [2]. Acute aortic dissections are those events recognized within 14 days of onset [3]. Dissections can be classified according to location of the initiation site; the Stanford classification system categorizes dissections into type-A which refers to dissections of the ascending and transverse aorta, and type-B which refers to dissections of the descending aorta [4].

Early control of dissections can change the disease progression and primarily involves pharmacologic control of flow, pressure, and shear stress [5]. Surgical interventions are necessary in type-A dissections, while thoracic endovascular aortic repair with covered grafts is usually reserved for type-B dissections [4,6]. In theory, using stent grafts blocks the false lumen, improves the perfusion of the true lumen, and reduces intramural stresses to pre-dissection levels. Although endovascular devices have $100 \%$ primary procedural success rate, long term prognosis of chronic type-B dissection is disappointing: $60-80 \%$ survival within 5 years since complications and aneurysm expansion are likely [2]. Approximately $25 \%$ of the treated patients

presenting type-B dissection experience malperfusion syndrome [7,8] or hemodynamic 


\section{AUTHOR ACCEPTED MANUSCRIPT}

instability, resulting in a high risk of early death if untreated [9]. Malperfusion syndrome typically leads to abdominal pain, lower limb ischemia, nausea, diarrhea, and paraplegia.

Covered grafts are implanted with partial coverage of dissection to minimize malperfusion leaving open re-entries, and result in recovery of the true lumen with subsequent false lumen thrombosis that may lead to aneurysms [10]. To overcome this limitation, the multilayer flow modulator (MFM) was designed to eliminate the false lumen and simultaneously suppress possible flow disruptions that can lead to malperfusion. The company manufacturing the MFM device (Cardiatis, Isnes, Belgium) has obtained CE marking approval (European Conformity) for treating un-ruptured complex aortic aneurysms (aortic aneurysm involving at least one branch artery). It is a self-expanding tubular stent composed of a three-dimensional (3D) mesh. MFM consists of several inter-connecting layers of a braided cobalt alloy wire (Phynox $\left.{ }^{\circledR}\right)$, and is extremely flexible and fatigue resistant. The meshed structure of the device allows proper perfusion of side branches while simultaneously it reduces the blood flow within the false lumen and aneurysms [11-13].

The biocompatibility of the MFM has already been tested in porcine models [14] and its role in treating complex aortic aneurysms has been well documented [13]. Although there are published qualitative reports of MFM in enhancing true lumen hemodynamics in dissection patients [15], to the best of our knowledge, few if any have concentrated on the distal perfusion consequences of MFM, alternative designs of MFM, the reentrant vascular connections between the false and true lumen, and their impact on device efficacy. The incorporation of these elements in this work allowed us to address: 1) the evolution of the false lumen over time, 2) the 


\section{AUTHOR ACCEPTED MANUSCRIPI}

hemodynamic performance for alternative MFM designs, and 3) the effect of flow share alteration as a result of using the alternative designs of MFM device. 


\section{Methods}

\section{AUTHOR ACCEPTED MANUSCRIPT}

\subsection{Geometrical Analysis}

\subsubsection{Imaging Data}

Two patients were selected on the polar ends of the spectrum of dissection (case 1 and case 2). Computed tomography (CT) scans (Siemens SOMATOM Dual Source CT Scanner) were acquired prior (pre) to the MFM implantation and post MFM implantation at day 3, months 2, 6

and 11 for case 1, and at day 3, months 3, 12, and 24 for case 2 (Table 1). Written informed consent was signed by the patients, and the local ethics committee approved the study. All medical images obtained by CT were anonymously saved in Digital Imaging and Communications in Medicine format.

In both cases the dissection started from the proximal descending aorta and ended just proximal to the iliac arteries with multiple re-entries between the true and false lumen. In case 1 only true lumen was connected to the iliac arteries, while in case 2 both true and false lumen were connected and supplied the right iliac artery with blood. The total number of re-entries, the pattern of distribution and geometrical characteristics differ in each case [case 1: 4 re-entries (diameter: min $3.5 \mathrm{~mm}$ and $\max 15 \mathrm{~mm}$ ), case 2: 3 re-entries (diameter: min $5 \mathrm{~mm}$ and $\max 33$ $\mathrm{mm})]$. All the major re-entries could be identified in the post MFM implantation CT scans and they were not affected by the MFM blooming artifact [16,17]. The MFM device was used to increase perfusion of the true lumen by almost covering the entire aortic dissection $(\sim 300 \mathrm{~mm}$ in case 1 and $\sim 340 \mathrm{~mm}$ in case 2 ). Case 1 had a major true lumen stenosis (minimum area of 26.3 $\mathrm{mm}^{2}$ ) at aortic zone 5 and the last re-entries of the false lumen were noticed at the abdominal 


\section{AUTHOR ACCEPTED MANUSCRIPT}

aortic area (zone 9). Case 2 had a severe true lumen stenosis (minimum area of $124.8 \mathrm{~mm}^{2}$ ) and the last re-entry of the false lumen was noticed at the right common iliac artery (zone 10). Thoracic aorta zones are classified according to Fillinger et al. [18] (Fig 1).

\subsubsection{Surface reconstruction}

To extract the 3D aortic surfaces we used a semi-automatic segmentation method which combines an in-house segmentation tool based on MATLAB (MathWorks, Natick, Mass) [19], commercially available VMTKlab software (VMTKlab OROBIX, v.1.5.1), and an open source segmentation software (3D Slicer v.4.0) (Fig 1). We removed small, hemodynamically lessimportant collateral arteries which are not always visible in both baseline and follow up CT scans (lumber arteries) using the Vascular Modelling Tool of VMTKLab, reconstructed nine outlets for each case, and stored geometries in stereolithography file format (Fig 1). The procedure was repeated for both cases using pre and post CT scans.

\subsubsection{MFM device reconstruction}

MFM implantation expands the true lumen allowing the device to come in contact with the aortic wall and the false lumen. Due to small size of MFM metallic wires $(<0.3 \mathrm{~mm})$, the comparatively-low resolution of imaging modality, the contact with the wall, and the blooming artifact of the metallic device [16], it was not feasible to reconstruct the MFM using the CT scans. Therefore, the MFM device was geometrically reconstructed and inserted within the aortas using the reconstructed post true lumen aortic surfaces as guidelines. The start and end point of each MFM device was marked in CT scans and matched to the reconstructed geometry. Then the centerline of the true lumen was extracted and each MFM wire was generated numerically 


\section{AUTHOR ACCEPTED MANUSCRIPT}

following a spatial helix curve along the centerline. To best fit the wires of the device to the true lumen surface we used the mean distance of the centerline point to the true lumen surface as radius of the helix. The MFM generation was done using a developed in-house MATLAB (MathWorks, Natick, Massachusetts, USA) code using the Frenet-Serret formulas. The result is a realistic 3D representation of the MFM device, which is in contact with the lumen in the majority of its length. Some parts of the device are not in full contact with the lumen due to the steep changes in the curvature of the lumen surface. Using the same method and only one layer of wires the single-layer device was produced for each case (Figs 1 and 2).

\subsection{Computational Analysis}

\subsubsection{Volumetric mesh construction}

Blood flow inside the aorta is modelled solving partial differential equations of Navier-Stokes

to conserve mass and momentum. The fluid domain is meshed using ANSYS ICEM CFD (ANSYS v16.0, Canonsburg, PA, USA) to divide the domain into unstructured tetrahedral elements and accurately capture the complicated geometrical features. The mesh is refined near the wall, MFM struts, and wherever high-curvature geometrical features exist; while coarsened towards the lumen center to keep computational costs at bay. The robust Octree algorithm of this software generates a mesh conformal to the geometry with a spatial subdivision approach. In this way, the algorithm will refine the mesh up to pre-set regional mesh size, filling tetrahedral elements within the volume generated by arterial wall and the MFM device, and respecting the gaps within. For pre cases less than ten million tetrahedral grids were generated (case 1: 2,396,764 and case 2: 998,415). For the post cases, due to the small size of devices and the 


\section{AUTHOR A CCEPTED MANUSCRIPT}

sophisticated design of their entangled wires, considerably high number of tetrahedral grids [case

1: 39,005,649 (post+single layer), and 99,012,347 (post+MFM) and case 2: 38,635,837

(post+single layer), and 153,150,005 (post+MFM)] were generated demanding substantially more number of computational grids to resolve the MFM boundary (Fig 2). Accordingly, the smallest element size near the MFM struts was $0.035 \mathrm{~mm}$, while the mesh was coarsened up to 3 $\mathrm{mm}$ in the center of lumen near the inlet to optimize the computations. Specifically, for post cases with MFM, the resolution of mesh around the device is a critical factor, to not only resolve the geometrical features of MFM, but also capture the hemodynamics in more details. To make sure that the shear stress is accurately resolved, a mesh independence study was performed. We refined the mesh and compared the velocity and wall shear stress (WSS) in selected crosssectional areas in two consecutive refinement set-ups of computational mesh to keep relative errors below 2\%. A boundary layer mesh is also made near the arterial walls and MFM wires to accurately calculate the stress metrics (Fig 3).

\subsubsection{Governing equations and flow modeling}

We solved the Navier-Stokes equations for time-dependent incompressible blood flow using a fully-coupled finite volume solver (ANSYS CFX, Canonsburg, PA, USA). The Rhie-Chow interpolation algorithm was applied to integral points of a co-located grid layout to calculate pressure-redistribution terms up to the third-order accuracy. To take into account the small shear strain values near the struts and rheological behavior of blood, it was modeled as a nonNewtonian incompressible fluid with density of $1060 \mathrm{~kg} / \mathrm{m} 3$ and shear dependent dynamic viscosity following the Carreau model $[20,21]$ : 


\section{AUTHOR A CCEPTED MANUSCRIPT}

$$
\frac{\mu-\mu_{\infty}}{\mu_{O}-\mu_{\infty}}=\left[1+(\lambda \cdot \dot{\gamma})^{2}\right]^{(n-1) / 2}
$$

Where $\dot{\gamma}$ is the scalar shear rate, $\mu_{O}$ and $\mu_{\infty}$ are the blood viscosities at infinite and zero shear rates, and $\lambda$ and $n$ values are Carreau parameters (Table 2) [22].

\subsubsection{Boundary conditions and numerical method}

A time-dependent inflow rate immediately after the sinotubular junction was extracted from the literature [23]. Unfortunately, accurate determination of the subject-specific inflow boundary condition for these real-patient cases requires a degree of invasiveness that is not used in clinical aortic dissection therapies since they increase the intervention risk. The MFM and vessels are assumed as no-slip walls. To avoid freezing the flow patterns by over constraining the boundary conditions with pre-specified pressures, e.g. zero pressure settings frequently practiced in hemodynamic simulation, we employed a lumped-parameter model (LPM) to dynamically update the outlet pressure based on peripheral resistances, proximal and distal to the outlet, and vascular compliance [23]. This method allowed mutable flow patterns to emerge and minimized the inaccuracy associated with unrealistic outlet boundary conditions. Embracing an electrical analogy of hemodynamic circulation, this classic LPM set-up, that we have recently adapted for aortic dissections [23], considers inductive, resistive and capacitance elements representing effects of inertia, fluid friction, and vascular distension and fluid storage, respectively. Based on this model, the outlet pressure is dynamically updated according to vascular hemodynamic patterns employing a modified circuit with extracted capacitive as well as characteristic and distal resistive elements [23-25]. 


\section{AUTHOR A CCEPTED MANUSCRIPT}

The cumbersome pre- and post-processing steps were performed on a high-performance work station (64-bit, Intel Xeon, 12 core, $1.8 \mathrm{GHz}$ with 192GB of RAM) and the computational runs were conducted on a local parallel system with 6 nodes composed of 28 dual-core CPUs. Iterations in each time step were terminated when the residuals of variables dropped below $10^{-6}$, to assure convergence, while mass convergence was also monitored externally. The hemodynamic features including velocity distribution, flow streamlines, and wall shear stress

map were analyzed using the ANSYS post processing package (CFD-Post, ANSYS v16.0, Canonsburg, PA, USA) and in-house subroutines. 


\section{Results}

We studied the evolution of the false lumen patency over time, reconstructing the relevant geometries from CT scans. False lumen evolution was quantified by measuring the volume of the reconstructed pre and post models and was noticeably reduced (case 2: 47\%) or even eliminated (case 1: 94.5\%) over time. The degree of reduction depends on the architecture of vasculature, the evolution stage of the aortic dissection, and how false and true lumen are connected (Fig 4). This two-fold difference in the false lumen evolution is due to the most distal (last) re-entry in case 2, which connects the right iliac artery to the false lumen and maintains the blood flow within it (Fig. 1). To study the post-procedural perfusion regain three planes perpendicular to the center line of the true lumen were defined for pre, post+1-layer and post+MFM simulations: at the beginning of the dissection just after the take-off of the great vessels (Descending Aorta: zone 3), in the middle of the descending aorta (Suprarenal - mid Aorta: zones: 4-5), and in the terminal aspect of the aortic dissection (Infrarenal Supra Femoral bifurcation: zone 9). The majority of aortic blood is channeled to flow in the true lumen after the implantation of both devices, which reduces the false lumen flow (Fig 5). Although, both devices significantly alter the perfusion pattern in favor of the true lumen, they preserve some perfusion to the false lumen, which is vital for a number of side branches that emanate from it (visible to post procedure CT scans).

To examine the global effect of using uncovered mesh stents for aortic dissection treatment, time-averaged WSS (TAWSS), as a prominent factor of hemodynamic performance, was calculated for each simulation over the entire arterial tree (Fig 6). TAWSS is calculated as [26]: 


$$
\begin{aligned}
& \text { AUTHOR A CCEPTED MANUSCRIPT } \\
& \qquad T A W S S=\frac{1}{T} \int_{0}^{T}\left|\overrightarrow{\tau_{w}}\right| d t
\end{aligned}
$$

where wall shear vector, $\tau_{w}$, is averaged over the cardiac cycle of period T. As there is a restriction for blood flow in the true lumen in pre-intervention cases, TAWSS is increased in the true lumen with higher stresses near the bifurcations and inner curves of the artery. Near the proximal entry to the false lumen hemodynamic patterns are significantly disrupted depicting pathological map of TAWSS. This localized hemodynamic stressors induce endothelial dysfunction, and promote inflammation and disease progression $[27,28]$. Both endovascular implants restored the true lumen flow, increasing the lumen area, and reduced the blood share of the false lumen, resulting in a global decrease of TAWSS in the true and false lumen. This alteration in general map of stress maintains a more physiological environment within the aorta. However, stagnation of flow in the vicinity of device struts reduces the TAWSS locally in both cases which may not be significantly atheroprone due to the low strut thickness. Distribution of TAWSS is not noticeably different comparing the post-intervention arteries with MFM and the single-layer device. However, in areas where less resistance against the blood flow was exerted by the 1-layer device compared with MFM, the increased velocity caused higher wall stresses.

Effects of localized flow pulsatility, as another predictor of clinical events, were also assessed comparing the oscillatory shear index (OSI) in each simulation (Fig 7).

$$
O S I=\frac{1}{2}\left(1-\frac{\left|\int_{0}^{T} \overrightarrow{\tau_{w}} d t\right|}{\int_{0}^{T}\left|\overrightarrow{\tau_{w}}\right| d t}\right)
$$

OSI distribution in pre-intervention simulations shows high pulsatility in the false lumen due to dramatic disruption caused by the aortic dissection. Non-physiological pattern of flow near the 


\section{AUTHOR A CCEPTED MANUSCRIPT}

proximal entry and also in abdominal aorta induces higher oscillation, and thus OSI. Similar to TAWSS, device implantation maintains the physiological pattern of blood flow, reducing the OSI in the false lumen and in the vicinity of vital organ outlets. The oscillation near the proximal entry, although reduced, still remains locally higher, specifically in single-layer cases, due to blood flow division between the true and false lumen. Comparing the single-layer with MFM cases, oscillation looks slightly higher in regions where high-velocity blood flows freely through the single-layer device.

To further investigate the differences of the two devices, we studied the local hemodynamic patterns. Flow disruption was qualitatively examined illustrating blood flow velocity streamlines to detect recirculation areas (Fig 8). Substantial flow disruption and recirculation are observed in the pre cases; specifically, immediately distal to the aortic arch. Flow disruption is partially alleviated in post-implantation models as the geometrical irregularities are decreased. However, localized recirculation is observed, even in in the peak-systolic time point, more frequently in single-layer case compared to MFM, particularly in areas with suboptimal apposition (e.g. proximal false lumen entry).

Based on above observations, we extracted the planar streamlines at critical regions to compare the single-layer device to MFM (Figs 9 and 10). To further highlight the effects of pulsatility, we extracted the results in different systolic and diastolic time points wherein the blood accelerates and decelerates. More intense patterns of recirculation were observed in deceleration phase of cardiac cycle in single-layer cases, wherein blood faced less resistance of device and got trapped between the implant and the vasculature. In addition to showing increased perfusion to the true lumen and reducing TAWSS, the MFM device forced blood to 


\section{AUTHOR ACCEPTED MANUSCRIPI}

concentrically stream inside the device (Fig 10). In contrast, the sparse design of single-layer mesh allowed blood to flow more diffusely in between the device struts. The design of entangled struts in MFM which channels the blood flow into the true lumen, considerably suppresses the blood recirculation compared to less effective single-layer device [11]. 


\section{AUTHOR A CCEPTED MANUSCRIPT}

\section{Discussion}

Aortic dissections are increasingly evident, yet challenging clinical conditions where technology availability has outstripped clinical insight. Fenestrated stent grafts are crucial for treating dissections and maintaining perfusion of distal aortic segments. However, in majority of cases stenting of a relatively long dissection makes it difficult to build an efficacious patientspecific device with proper design of connections to all branched arteries [29]. Aortic dissections represent complex pathological events - far more consequential than mere destruction of arterial wall. Initiation of secondary pathways and inter-lumen connections between the true and false lumen establish complex blood flow patterns that can perfuse the upper extremities and brain, as well as the lower extremities and vital organs. In the latter case, tissue integrity depends to its greatest extent on which lumen feeds the organ in question. Thus, vascular interventions that restore true lumen flow at the expense of the false lumen may in fact jeopardize vital organs. It is not sufficient to simply reduce the false lumen - one must preserve organ perfusion and at times this requires preservation of aortic branches that assure spinal cord integrity [30] and interlumenal communicating arteries that assure organ vitality.

Covered stents necessarily obstruct these vessels, mesh stents do not, but vascular access alone is not sufficient to provide best flow restoration. We now show that device geometry should seek to assure perfusion not just architectural correction (Figs 4 and 5). It is the optimization of inartery fluid dynamics that assures resumption of homeostasis. The two cases we examined, represent the extremes that support this concept. Though they affect luminal architecture to considerably variable degree - literally two-fold difference on effects on the false lumen - their net impact is substantial and equivalent in both cases because they both assure efficient perfusion 


\section{AUTHOR A CCEPTED MANUSCRIPT}

regain to vital organs and distal flow patterns. It is not the lumen of the aorta, but down stream flow that dominates health.

Like porous screens and honeycomb nets that reduce turbulence and flow perturbations in wind tunnels [31], the MFM device as a three-dimensional braided wire mesh, laminarizes blood flow, reduces the perturbations, and focuses the streamlines in the direction of vascular wall. This substantial change in hemodynamic patterns eliminates the vortices, and reduces shear stresses in both the true and false lumen (Fig 6), inhibiting aneurysmal growth, and greatly reducing rupture risk [11]. The real impact though requires a more thorough understanding of fluid dynamics at play. TAWSS alone is insufficient to describe the variable impact of single- and multilayer implants given the oscillatory nature of flow. OSI maps demonstrate significant improvement in oscillation and disruption suppression by device implantation (Fig 7). More importantly, patterns of OSI show that the more-porous design of the single-layer device allows the high-velocity blood jet diffuse through the struts and induce local wall impingement and recirculation in selected areas (Fig 7). Laminar flow alignment in critical segments with flow recirculation is highly affected by multilayer design of MFM and relative positioning of device in complex geometries. Our observations, comparing the single-layer mesh to typical design of MFM, show generation of localized recirculation zones in the vicinity of large inter-strut cells (Figs 8). Increased filtration of blood flow through sparse single-layer mesh structure, at specific time points of cardiac cycle, in segments with high curvature or near inter-lumen re-entries acts as a local source of adverse outcomes including flow disruption and false lumen evolution (Fig 9 and Fig 10). Based on our results, the flow is more susceptible to induce unfavorable recirculation zones in decelerating phases of cardiac cycle when phase change occurs. There are many ways to restore true lumen flow and reduce false lumen share, but there are few (if any) ways of aligning flow, retaining the 


\section{AUTHOR A CCEPTED MANUSCRIPT}

flow to the great vessels above and the lower extremity below, and reducing WSS with minimal flow disruption and recirculation. This is the advantage of a multilayer implant that directly affects flow.

Although vital organ perfusion and global patterns of hemodynamics are similarly improved employing the single-layer and MFM devices, they perform differently based on the vascular geometry and procedural factors (device length, apposition, outlet coverage etc.). From hemodynamic point of view, we observed that in highly tortuous arteries with varying apposition, the high-velocity streaming of blood flow through single struts induces localized flow instability and recirculation in the single-layer cases. This flow pattern then changes the local distribution of shear metrics, i.e. TAWSS and OSI, promoting adverse clinical events. MFM is also reported in clinical practice to be superior in rapid promotion of re-endothelialization when compared with the single-layer device and contemporary stents [32]. The laminarized flow promoted by MFM and reduced local perturbation not only stimulate organized thrombus formation, but also accelerate the device coverage and integration, minimizing endothelium dysfunction, and thus regulating vascular hemostasis, cell signaling, and vascular healing.

As with any research and modeling, there are approach limitations. The most important limiting factor in our simulation is that we cannot access patient-specific boundary conditions. Accurate determination of such measures requires a degree of invasiveness, which is not only not used in clinical dissection scenarios but may place these patients at risk and has therefore rarely appeared in the literature. There have been attempts to compare the results of numerical simulations to in vivo measurements [34,35]. These studies are though limited to pre-surgical dissection cases without considering the effect of endovascular devices. Although lumped- 


\section{AUTHOR A CCEPTED MANUSCRIPT}

parameter models are extensively being used to assign boundary conditions at outlets $[35,36]$, their corresponding parameters in terms of resistances and compliances are mainly acquired for cases without dissection - this may or may not deem appropriate for subject-specific dissection simulations. Another limitation of this study is considering flow-only simulations and ignoring the effects of aortic wall motion. Wall distensibility and movement during the cardiac cycle might affect the disease progression as wall stresses in the media layer were shown to predict the tear onset and dissection propagation [37,38]. Fluid-structure interaction (FSI) modeling, however, requires accurate differentiation between material properties of diseased and healthy tissue in a dissected artery, accurate structural models of heterogeneous tissue, and large computational resources. Thus, FSI simulations are limited to extremely-simplified geometries or oversimplified material models ignoring the endovascular implants. More importantly for cases with relativelylong endovascular implants with a complex geometry, e.g. MFM with more than a hundred million computational grids, available computational resources would not furnish adequate power to perform FSI within a reasonable amount of time. In addition, MFM implantation stiffens the arterial wall, making the rigid wall assumption valid for flow analysis purposes. Thus, FSI can only be complied if disease progression is to be included in simplified models.

Although we had access to and reconstructed several follow-up time points for each patient, we have conducted simulations only immediately after intervention. The reason was twofold: the MFM device is, as mentioned, rapidly endothelialized [33] after the implantation, making the reconstruction of realistic MFM models extremely difficult, and we wanted to study the flow alterations caused by the device right after the implantation. Therefore, the alterations observed in flow patterns and the recorded reduction of false lumen perfusion resulted from our simulations mainly arise from device implantation. Furthermore, the evolution of the false lumen and how the 


\section{AUTHOR ACCEPTED MANUSCRIPT}

change of flow pattern and ultimately the flow share distribution as a result of device implantation

might affect it, are of great value to clinicians. Reconstructing the follow-up data, we monitored the geometrical change of the false lumen in different time points, which is affected by the altered flow pattern. The false lumen reduction is an event that initiates immediately after the MFM implantation and is the consequence of opening the true lumen and subsequent change in aortic hemodynamics. The true lumen opening reduces flow in the false lumen (Fig 5), increases the blood flow through the true lumen (Fig 5 and Fig 8), and alters the WSS and flow patterns (Fig 6 and Fig 8). This mechanism ultimately results in the false lumen shrinkage, as recorded in followup data. This then becomes one of the primary teachings of this work-device compression of the false lumen goes a long way to restoring vascular integrity in aortic dissections but benefits can be significantly reduced if the structural alterations retain significant shunted flow to distal vessels, as seen in case 2 herein. False lumen retraction was markedly accelerated when the MFM covered collateral connections between the true and false lumen. It was, however, significantly delayed when the false lumen inserted into a major peripheral vessel with origin above and terminus below the device. Physical modeling then provides valuable insight to the surgeon as to expected effect.

Attaining unsteady flow patterns, performing FSI in simplified models, assessing more sophisticated alternative designs of endovascular devices, and modeling numerous categories of aortic dissection patients are feasible - yet restricted by computational resources. This, in part, leads to studies with limited number of cases and simplified models. 


\section{AUTHOR ACCEPTED MANUSCRIPT}

\section{Conclusions}

Computational study of blood flow in aortic dissection cases altered by flow modulator devices adds great insight to the hemodynamics of aortic dissection. While single-layer mesh stents can support true lumen and sufficiently restore physiological perfusion, they result in slightly higher WSS distribution and local recirculation, particularly in complex arterial geometries and areas with suboptimal device apposition. The transition from systolic to diastolic phases of the cardiac cycle, leads to amplified flow disruption and instability observed in aortic dissection and singlelayer stent therapies, highlighting the importance of inherent pulsatility of flow in aorta and need to model the entire cardiac cycle. Single-layer devices might also associate with procedural difficulties to scaffold the artery and maintain the patency of true lumen due to low structural strength, and inferior safety and delayed healing, compared to MFM, due to delayed reendothelialization. A multilayer implant like MFM overcomes these drawbacks. The focus on aortic dissections should be directed not just to the evident vascular changes but also to the spatial distribution and coverage of re-entries between the true and false lumen, the perfusion of side branches, and architecture. Devices should now be expected to affect the general flow pattern well beyond implantation site by focalizing the flow inside the device, suppressing the recirculation zones, and permitting the side branch perfusion.

\section{Acknowledgments}

Cardiatis provided access to data and partial funding for LA. ERE and FRN were funded in part by a grant from the National Institutes of Health (R01 503 GM49039). 


\section{References}

\section{AUTHOR ACCEPTED MANUSCRIPT}

[1] F.J. Criado, Aortic dissection: a 250-year perspective, Tex Hear. Inst J. 38 (2011) 694700. http://www.ncbi.nlm.nih.gov/pubmed/22199439.

[2] R. Fattori, P. Cao, P. De Rango, M. Czerny, A. Evangelista, C. Nienaber, H. Rousseau, M. Schepens, Interdisciplinary expert consensus document on management of type B aortic dissection, J. Am. Coll. Cardiol. 61 (2013) 1661-1678. doi:10.1016/j.jacc.2012.11.072.

[3] A.C. Braverman, Acute aortic dissection: clinician update, Circulation. 122 (2010) 184188. doi:10.1161/CIRCULATIONAHA.110.958975.

[4] L.F. Hiratzka, G.L. Bakris, J.A. Beckman, R.M. Bersin, V.F. Carr, D.E. Casey Jr., K.A. Eagle, L.K. Hermann, E.M. Isselbacher, E.A. Kazerooni, N.T. Kouchoukos, B.W. Lytle, D.M. Milewicz, D.L. Reich, S. Sen, J.A. Shinn, L.G. Svensson, D.M. Williams, 2010 ACCF/AHA/AATS/ACR/ASA/SCA/SCAI/SIR/STS/SVM Guidelines for the diagnosis and management of patients with thoracic aortic disease. A Report of the American College of Cardiology Foundation/American Heart Association Task Force on Practice Guidelines, A, J. Am. Coll. Cardiol. 55 (2010) e27-e129. doi:10.1016/j.jacc.2010.02.015.

[5] R. Erbel, F. Alfonso, C. Boileau, O. Dirsch, B. Eber, A. Haverich, H. Rakowski, J. Struyven, K. Radegran, U. Sechtem, J. Taylor, C. Zollikofer, W.W. Klein, B. Mulder, L.A. Providencia, Diagnosis and management of aortic dissection, Eur. Heart J. 22 (2001) 1642-1681. doi:10.1053/euhj.2001.2782.

(C) 2019 International Federation for Medical and Biological Engineering 


\section{AUTHOR A CCEPTED MANUSCRIPT}

[6] I.M. Nordon, R.J. Hinchliffe, I.M. Loftus, R.A. Morgan, M.M. Thompson, Management of acute aortic syndrome and chronic aortic dissection, Cardiovasc Interv. Radiol. 34 (2011) 890-902. doi:10.1007/s00270-010-0028-3.

[7] A. Vendrell, J. Frandon, M. Rodiere, O. Chavanon, J.P. Baguet, I. Bricault, B. Boussat, G.R. Ferretti, F. Thony, Aortic dissection with acute malperfusion syndrome: Endovascular fenestration via the funnel technique, J Thorac Cardiovasc Surg. 150 (2015) 108-115. doi:10.1016/j.jtcvs.2015.03.056.

[8] M. Midulla, R. Fattori, J.P. Beregi, M. Dake, H. Rousseau, Aortic dissection and malperfusion syndrome: a when, what and how-to guide, Radiol Med. 118 (2013) 74-88. doi:10.1007/s11547-012-0815-9.

[9] S. Trimarchi, K.A. Eagle, C.A. Nienaber, R.E. Pyeritz, F.H.W. Jonker, T. Suzuki, P.T. O’Gara, S.J. Hutchinson, V. Rampoldi, V. Grassi, E. Bossone, B.E. Muhs, A. Evangelista, T.T. Tsai, J.B. Froehlich, J. V Cooper, D. Montgomery, G. Meinhardt, T. Myrmel, G.R. Upchurch, T.M. Sundt, E.M. Isselbacher, I.R.A. Aortic, Importance of Refractory Pain and Hypertension in Acute Type B Aortic Dissection Insights From the International Registry of Acute Aortic Dissection (IRAD), Circulation. 122 (2010) 1283-1289. doi:10.1161/Circulationaha.109.929422.

[10] C.A. Nienaber, S. Kische, H. Rousseau, H. Eggebrecht, T.C. Rehders, G. Kundt, A. Glass, D. Scheinert, M. Czerny, T. Kleinfeldt, B. Zipfel, L. Labrousse, R. Fattori, H. Ince, Endovascular repair of type B aortic dissection: long-term results of the randomized investigation of stent grafts in aortic dissection trial, Circ Cardiovasc Interv. 6 (2013) 


\section{AUTHOR A CCEPTED MANUSCRIPTI}

407-416. doi:10.1161/CIRCINTERVENTIONS.113.000463.

[11] S. Sultan, N. Hynes, E.P. Kavanagh, E.B. Diethrich, How does the multilayer flow modulator work? the science behind the technical innovation, J. Endovasc. Ther. 21 (2014) 814-821. doi:10.1583/14-4858.1.

[12] S. Sultan, N. Hynes, Multilayer flow modulator stent technology: a treatment revolution for US patients?, Expert Rev Med Devices. 12 (2015) 217-221. doi:10.1586/17434440.2015.1030339.

[13] C.D. Vaislic, J.N. Fabiani, S. Chocron, J. Robin, V.S. Costache, J.P. Villemot, J.M. Alsac, P.N. Leprince, T. Unterseeh, E. Portocarrero, Y. Glock, H. Rousseau, One-year outcomes following repair of thoracoabdominal aneurysms with the multilayer flow modulator: report from the STRATO trial, J Endovasc Ther. 21 (2014) 85-95. doi:10.1583/134553R.1.

[14] S. Sultan, E.P. Kavanagh, N. Hynes, E.B. Diethrich, Evaluation of functionality and biological response of the multilayer flow modulator in porcine animal models, Int Angiol. 35 (2016) 31-39. http://www.ncbi.nlm.nih.gov/pubmed/26044840.

[15] F. Stefanov, S. Sultan, L. Morris, A. Elhelali, E.P. Kavanagh, V. Lundon, M. Sultan, N. Hynes, Computational fluid analysis of symptomatic chronic type B aortic dissections managed with the Streamliner Multilayer Flow Modulator, J Vasc Surg. (2016). doi:10.1016/j.jvs.2016.07.135.

[16] U. Hoffmann, M. Ferencik, R.C. Cury, A.J. Pena, Coronary CT angiography, J Nucl Med. (C) 2019 International Federation for Medical and Biological Engineering 


\section{AUTHOR A CCEPTED MANUSCRIPT}

47 (2006) 797-806. http://www.ncbi.nlm.nih.gov/pubmed/16644750.

[17] L.S. Athanasiou, D.I. Fotiadis, L.K. Michalis, Atherosclerotic Plaque Characterization Methods Based on Coronary Imaging, Elsevier Science, 2017. https://books.google.com/books/about/Atherosclerotic_Plaque_Characterization.html?id= SgVQCwAAQBAJ\&hl=en (accessed June 17, 2017).

[18] M.F. Fillinger, R.K. Greenberg, J.F. McKinsey, E.L. Chaikof, Reporting standards for thoracic endovascular aortic repair (TEVAR), J Vasc Surg. 52 (2010) 1022-33, 1033 e15. doi:10.1016/j.jvs.2010.07.008.

[19] L. Athanasiou, G. Rigas, A.I. Sakellarios, T.P. Exarchos, P.K. Siogkas, C.V. Bourantas, H.M. Garcia-Garcia, P.A. Lemos, B.A. Falcao, L.K. Michalis, O. Parodi, F. Vozzi, D.I. Fotiadis, Three-dimensional reconstruction of coronary arteries and plaque morphology using CT angiography - comparison and registration with IVUS, BMC Med. Imaging. 16 (2016). doi:Artn 9 10.1186/S12880-016-0111-6.

[20] F. Rikhtegar, C. Wyss, K.S. Stok, D. Poulikakos, R. Muller, V. Kurtcuoglu, Hemodynamics in coronary arteries with overlapping stents, J Biomech. 47 (2014) 505511. doi:10.1016/j.jbiomech.2013.10.048.

[21] S. Chien, S. Usami, H.M. Taylor, J.L. Lundberg, M.I. Gregersen, Effects of hematocrit and plasma proteins on human blood rheology at low shear rates., J. Appl. Physiol. 21 (1966). http://jap.physiology.org/content/21/1/81 (accessed April 20, 2017).

[22] F. Abraham, M. Behr, M. Heinkenschloss, Shape optimization in steady blood flow: a (C) 2019 International Federation for Medical and Biological Engineering 


\section{AUTHOR ACCEPTED MANUSCRIPT}

numerical study of non-Newtonian effects, Comput Methods Biomech Biomed Engin. 8 (2005) 127-137. doi:10.1080/10255840512331388588.

[23] F. Rikhtegar Nezami, L.S. Athanasiou, J.M. Amrute, E.R. Edelman, Multilayer flow modulator enhances vital organ perfusion in type B aortic dissection patients, Am. J. Physiol. Circ. Physiol. (2018) ajpheart.00199.2018. doi:10.1152/ajpheart.00199.2018.

[24] J. Alastruey, N. Xiao, H. Fok, T. Schaeffter, C.A. Figueroa, On the impact of modelling assumptions in multi-scale, subject-specific models of aortic haemodynamics., J. R. Soc. Interface. 13 (2016) 20160073. doi:10.1098/rsif.2016.0073.

[25] N. Xiao, J. Alastruey, C. Alberto Figueroa, A systematic comparison between 1-D and 3D hemodynamics in compliant arterial models., Int. j. Numer. Method. Biomed. Eng. 30 (2014) 204-31. doi:10.1002/cnm.2598.

[26] F. Rikhtegar, J.A. Knight, U. Olgac, S.C. Saur, D. Poulikakos, W. Marshall, P.C. Cattin, H. Alkadhi, V. Kurtcuoglu, Choosing the optimal wall shear parameter for the prediction of plaque location-A patient-specific computational study in human left coronary arteries., Atherosclerosis, 221 (2012) 432-7. doi:10.1016/j.atherosclerosis.2012.01.018.

[27] S.S. Dhawan, R.P. Avati Nanjundappa, J.R. Branch, W.R. Taylor, A.A. Quyyumi, H. Jo, M.C. McDaniel, J. Suo, D. Giddens, H. Samady, Shear stress and plaque development., Expert Rev. Cardiovasc. Ther. 8 (2010) 545-56. doi:10.1586/erc.10.28.

[28] Y.S. Chatzizisis, A.U. Coskun, M. Jonas, E.R. Edelman, C.L. Feldman, P.H. Stone, Role of endothelial shear stress in the natural history of coronary atherosclerosis and vascular 


\section{AUTHOR A CCEPTED MANUSCRIPTI}

remodeling: molecular, cellular, and vascular behavior, J. Am. Coll. Cardiol. 49 (2007) 2379-2393. doi:S0735-1097(07)01220-X [pii]10.1016/j.jacc.2007.02.059.

[29] S. Trimarchi, K.A. Eagle, Thoracic Endovascular Aortic Repair in Acute and Chronic Type B Aortic Dissection, JACC Cardiovasc Interv. 9 (2016) 192-194. doi:10.1016/j.jcin.2015.11.033.

[30] B. Rylski, M. Czerny, M. Südkamp, M. Russe, M. Siep, F. Beyersdorf, Fenestrated and Branched Aortic Grafts., Dtsch. Arztebl. Int. 112 (2015) 816-22. doi:10.3238/arztebl.2015.0816.

[31] J. Groth, A. V. Johansson, Turbulence reduction by screens, J. Fluid Mech. 197 (1988) 139. doi:10.1017/S0022112088003209.

[32] S. Sultan, E.P. Kavanagh, M. Bonneau, C. Kang, A. Alves, N.M. Hynes, Kinetics of endothelialization of the multilayer flow modulator and single-layer arterial stents, Vascular. 24 (2016) 78-87. doi:10.1177/1708538115585073.

[33] S.S. Edel P Kavanagh, E.P. Kavanagh, M. Bonneau, C. Kang, A. Alves4, N. Hynes, Assessment of Biocompatibility of the Multilayer Flow Modulator with Differing Thread Designs, J. Vasc. Med. Surg. 02 (2014). doi:10.4172/2329-6925.1000167.

[34] P.A. Rudenick, P. Segers, V. Pineda, H. Cuellar, D. García-Dorado, A. Evangelista, B.H. Bijnens, False Lumen Flow Patterns and their Relation with Morphological and Biomechanical Characteristics of Chronic Aortic Dissections. Computational Model Compared with Magnetic Resonance Imaging Measurements, PLoS One. 12 (2017) 


\section{AUTHOR A CCEPTED MANUSCRIPT}

e0170888. doi:10.1371/journal.pone.0170888.

[35] D. Dillon-Murphy, A. Noorani, D. Nordsletten, C.A. Figueroa, Multi-modality imagebased computational analysis of haemodynamics in aortic dissection, Biomech. Model. Mechanobiol. 15 (2016) 857-876. doi:10.1007/s10237-015-0729-2.

[36] M. Alimohammadi, O. Agu, S. Balabani, V. Díaz-Zuccarini, Development of a patientspecific simulation tool to analyse aortic dissections: assessment of mixed patient-specific flow and pressure boundary conditions., Med. Eng. Phys. 36 (2014) 275-84. doi:10.1016/j.medengphy.2013.11.003.

[37] M. Alimohammadi, J.M. Sherwood, M. Karimpour, O. Agu, S. Balabani, V. DíazZuccarini, Aortic dissection simulation models for clinical support: fluid-structure interaction vs. rigid wall models, Biomed. Eng. Online. 14 (2015) 34. doi:10.1186/s12938-015-0032-6.

[38] K. Khanafer, R. Berguer, Fluid-structure interaction analysis of turbulent pulsatile flow within a layered aortic wall as related to aortic dissection, J. Biomech. 42 (2009) 26422648. doi:10.1016/j.jbiomech.2009.08.010.

(C) 2019 International Federation for Medical and Biological Engineering 


\section{Authors biography}

\section{AUTHOR ACCEPTED MANUSCRIPT}

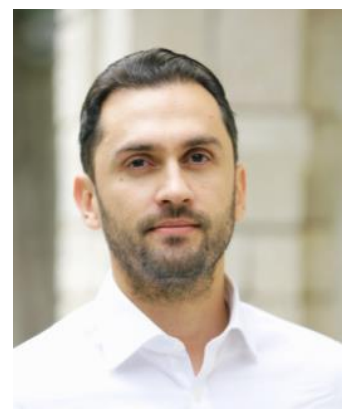

Lambros Athanasiou received his $\mathrm{PhD}$ degree from the University of Ioannina, Greece in 2015, where he conducted research in cardiovascular imaging using machine learning and image processing. He is currently working as a Postdoctoral Research Fellow at the Institute for Medical Engineering \& Science, MIT, Cambridge, MA, and at the Brigham and Women's Hospital, Boston, MA. His research interests include medical image processing, machine learning, biomedical engineering, decision support, and medical expert systems.

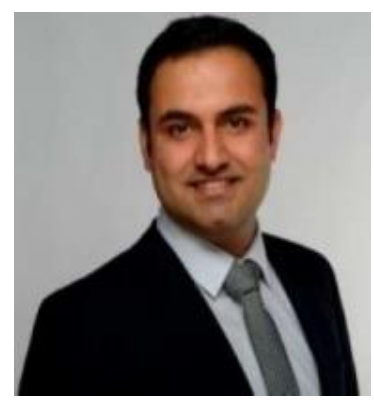

Farhad Rikhtegar Nezami, received Master's at Sharif University of Technology in Tehran, and $\mathrm{PhD}$ in Mechanical engineering from ETH Zurich, where he conducted research on hemodynamics and drug transport in stented coronary arteries. He is currently a postdoctoral associate and project leader in the Harvard-MIT Health Science and Technology Division. He is interested in a mechanistic understanding of human pathophysiology, translation of preclinical experiments to clinical practices, design and optimization of medical devices, and developing translational engineering and informatics platforms. 


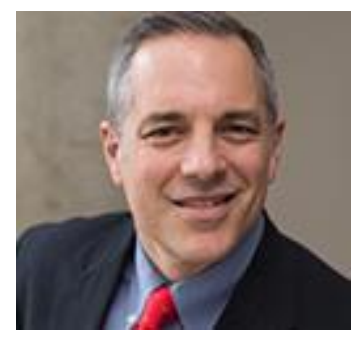

\section{AUTHOR ACCEPTED MANUSCRIPT}

Elazer R. Edelman, MIT Poitras Professor of Medical Engineering and Science, Harvard Medical School Professor of Medicine, and a Senior Attending Physician at the Brigham and Women's Hospital. He directs MIT's Institute for Medical Engineering and Science (IMES) and Clinical Research Center (CRC) as well as the Harvard-MIT Biomedical Engineering Center (BMEC) - all dedicated to applying the rigors of the physical sciences to elucidate fundamental biologic processes and mechanisms of disease. His research melds his clinical and research training to study biomaterials, drug delivery, implanted devices, and mechanical support. 


\section{AUTHOR ACCEPTED MANUSCRIPT}

\section{Figures}

Fig 1: 3D aortic surfaces (red) of case 1 and case 2 reconstructed using CT data. From left to right: pre MFM implantation aorta showing the aortic zones (0-9) [18] and outlets, post implantation aorta without the MFM, post implantation aorta including MFM (gray). Case 1: (Right top) an in view of post true lumen without and with MFM (gray) showing the re-entries (yellow), and (right bottom) pre and post MFM (gray) showing the true and false lumen. Case 2: (Right top) an in view of post true lumen without and with MFM (gray), and (right bottom) an in view of the right iliac artery showing its connection with true and false lumen (yellow box). TL: true lumen, FL: false lumen, $\mathrm{C} 1$ : case 1, C2: case 2, MFM: multilayer flow modulator, A: Brachiocefalic, B: Left common carotid artery, C: Left subclavian artery, D: Coeliac trunk, E: Superior mesenteric artery, F: Left renal artery, G: Right renal artery, H: Left common iliac artery and I: Right common iliac artery.

Fig 2: Generation of the single-layer and multilayer flow modulator (MFM) devices along the true lumen (TL) centerline: wires of MFM device are constructed concentrically to the centerline.

Fig 3: A cross-section of the constructed volume mesh of true lumen (left) and the magnified area showing the location of the device struts inside the mesh (right).

Fig 4: Evolution of the false lumen after the MFM implantation, C1: case 1, C2: case 2. 


\section{AUTHOR A CCEPTED MANUSCRIPT}

Fig 5: Perfusion regain of multilayer flow modulator (MFM) within the aortic dissection: true (left) and false (right) lumen: mass flow distribution of three perpendicular aortic planes at peak systole [Descending Aorta: Desc Ao (zone 3), Suprarenal - mid Aorta : MidAo SR (zone 5), and Infrarenal Supra Femoral bifurcation: IR SB (zone 9)] for case 1 (C1, top) and case 2 (C2, bottom) pre and post implantation of the MFM and single-layer (1L-mesh) device.

Fig 6: Time-averaged wall shear stress (TAWSS) distribution for case 1 (top) and case 2 (bottom) in pre-intervention (pre), post-intervention with the multilayer flow modulator (Post+MFM), and post-intervention with the single-layer device (Post+1-Layer).

Fig 7: Oscillatory shear index (OSI) distribution for case 1 (top) and case 2 (bottom) in preintervention (pre), post-intervention with the multilayer flow modulator (Post+MFM), and postintervention with the single-layer device (Post+1-Layer).

Fig 8: Blood flow streamlines for case 1 (top) and case 2 (bottom) in pre-intervention (pre), postintervention with the multilayer flow modulator (Post+MFM), and post-intervention with the single-layer device (Post+1L-mesh).

Fig 9: A coronal plane showing the flow pattern at different time points of cardiac cycle using the single-layer device (1-Layer, bottom) and the multilayer flow modulator (MFM, top).

Fig 10: An axial plane showing the flow pattern at different time points of cardiac cycle using the single-layer device (1-Layer, bottom) and the multilayer flow modulator (MFM, top).

\section{Tables}




\section{AUTHOR ACCEPTED MANUSCRIPT}

Table 1: Clinical data of patients used in model reconstructions including patient gender, age, follow-up time points, locations of entry and re-entry tears, and multilayer flow modulator (MFM) device. Location zones of the thoracic aorta are classified according to Fillinger et al.[18] and are shown in Fig 1.

Table 2: Carreau parameters to model non-Newtonian blood [20-22]. 


\section{AUTHOR ACCEPTED MANUSCRIPT}

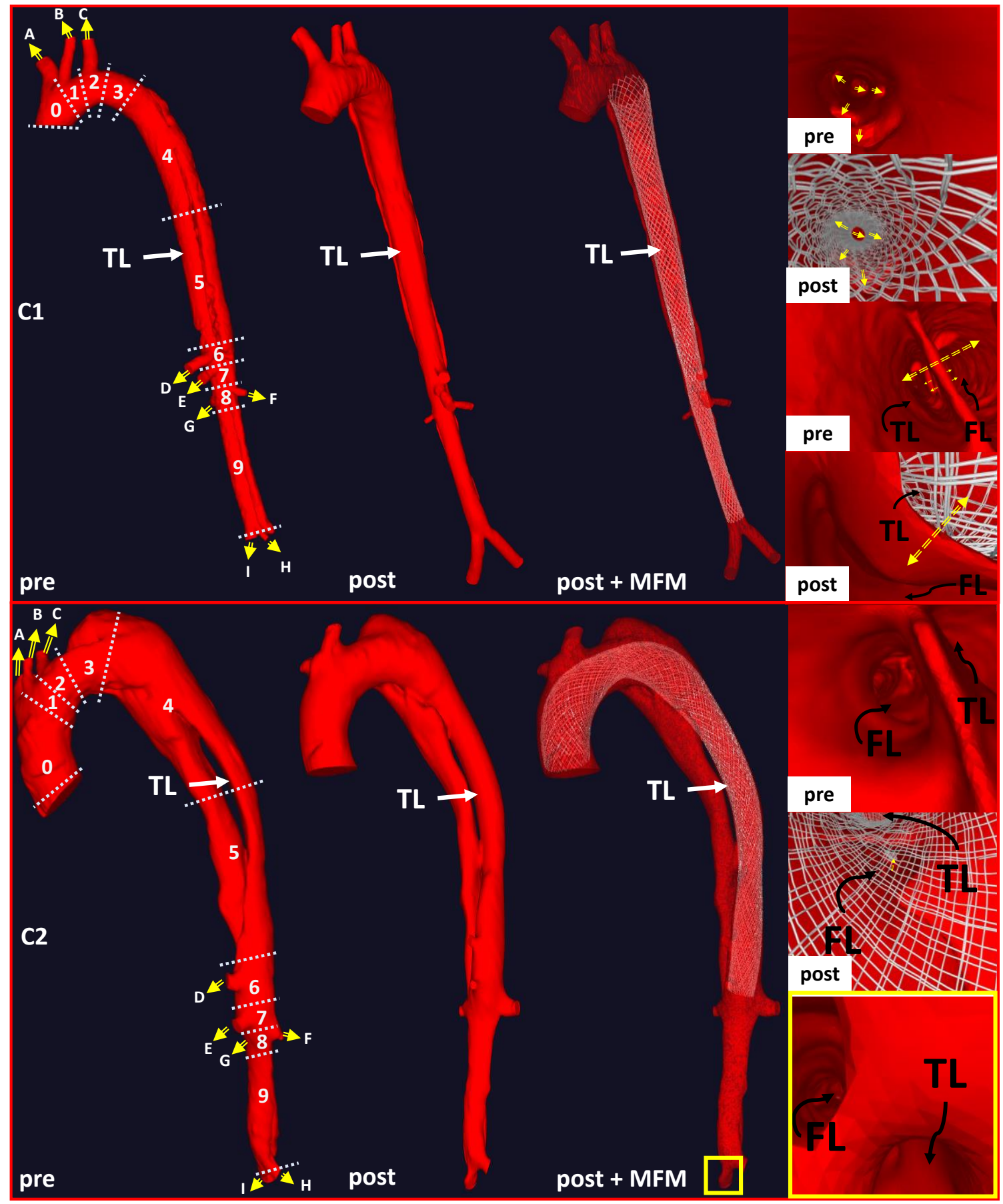

Fig 1

(C) 2019 International Federation for Medical and Biological Engineering 
AUTHOR ACCEPTED MANUSCRIPT

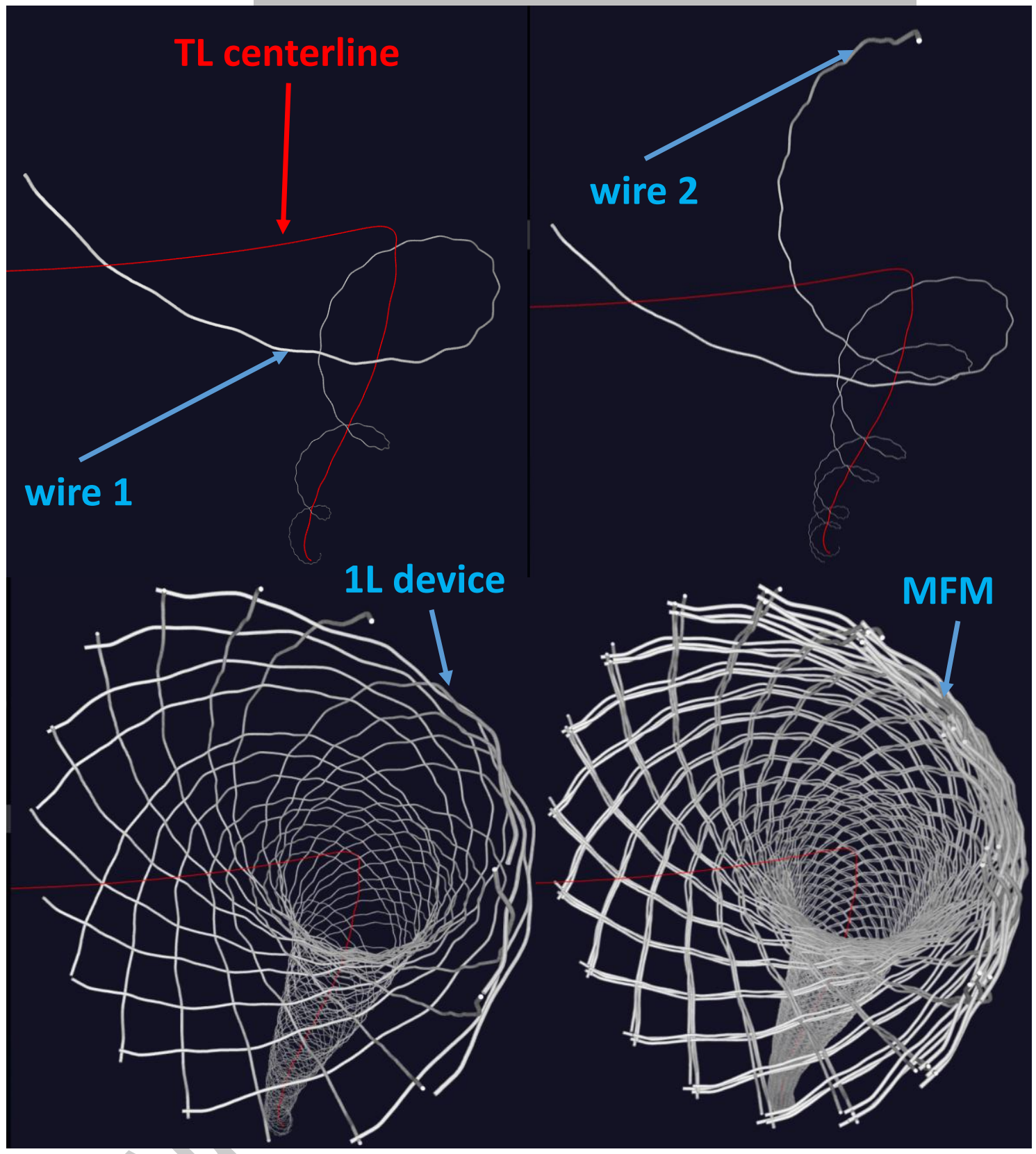

Fig 2

(C) 2019 International Federation for Medical and Biological Engineering 


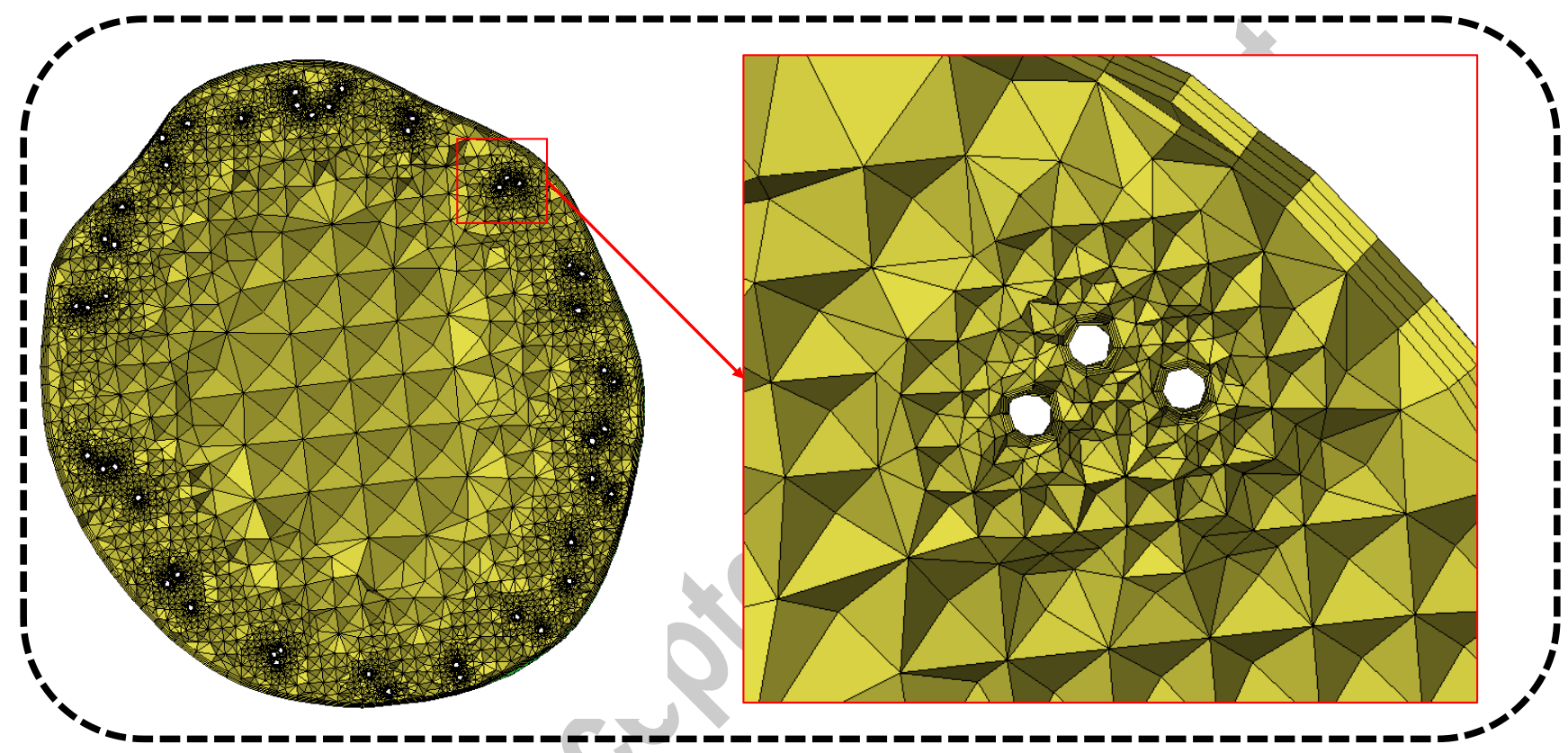

Fig 3

(c) 2019 International Federation for Medical and Biological Engineering 


\section{AUTHOR ACCEPTED MANUSCRIPT}

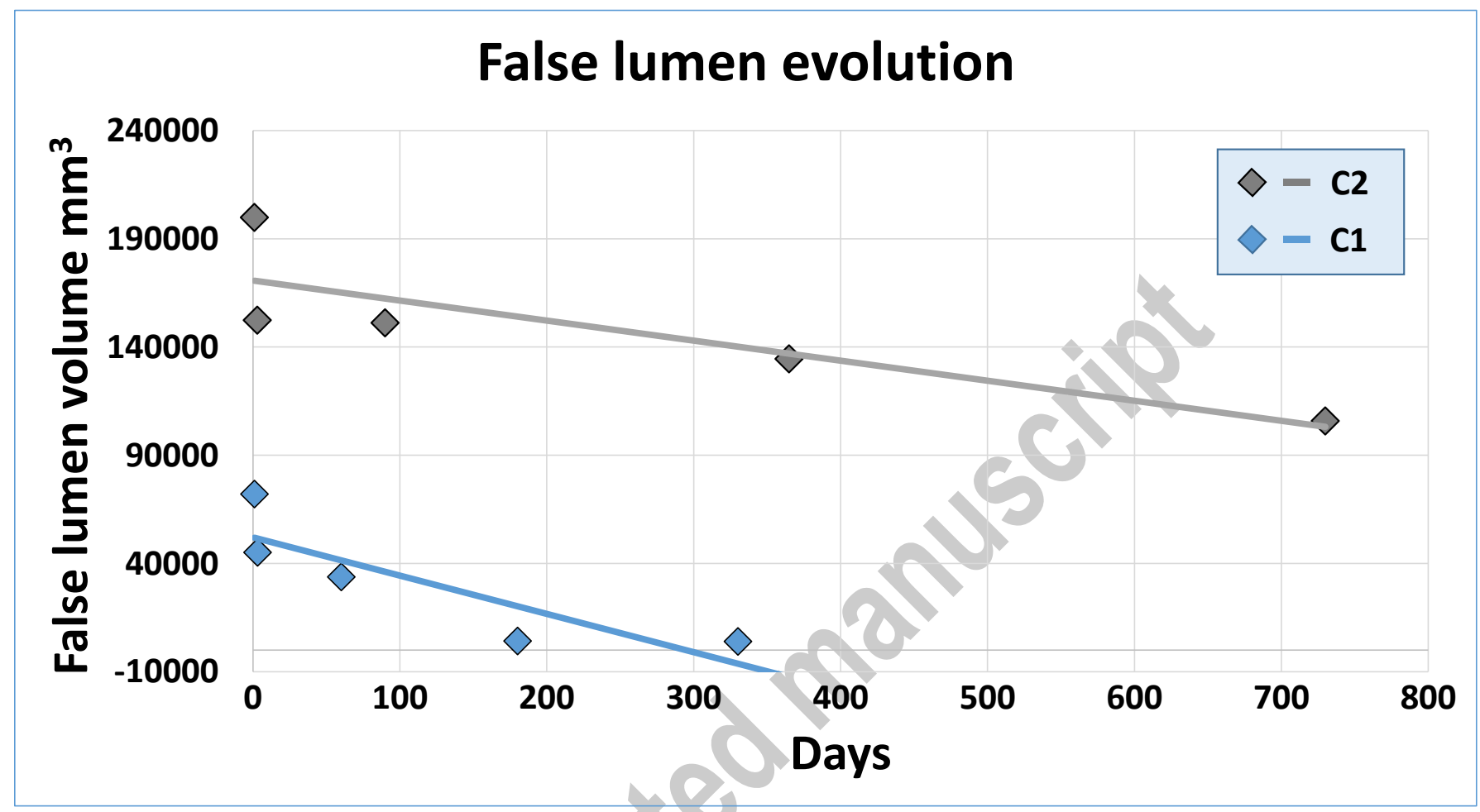

Fig 4 


\section{AUTHOR ACCEPTED MANUSCRIPTI}

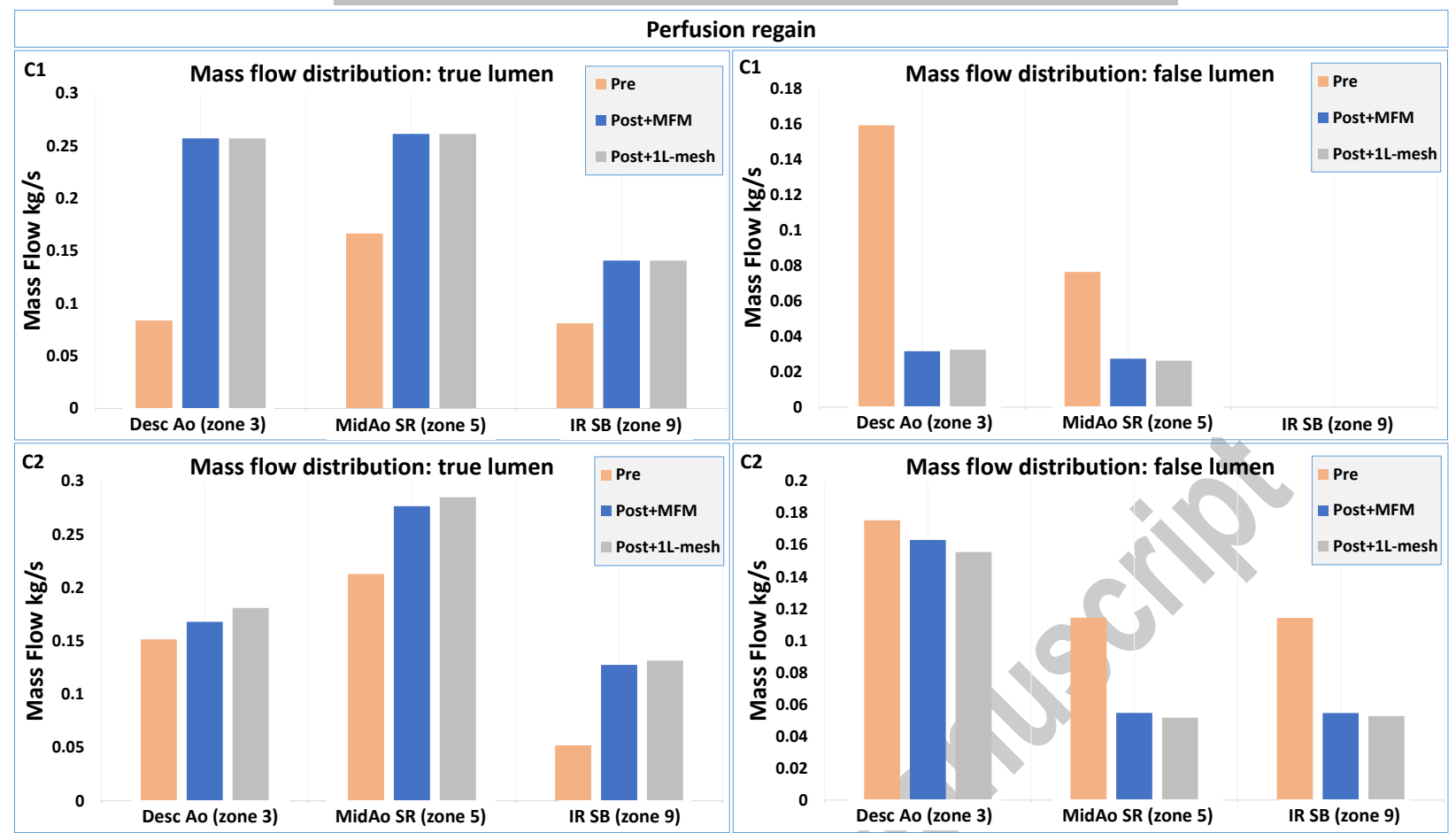

Fig 5 
AUTHOR ACCEPTED MANUSCRIPI

\begin{tabular}{|l|l|l|l|l|}
\hline \multicolumn{2}{|c|}{ pre Post+MFM } \\
\hline Anterior view & Posterior view & Anterior view Posterior view \\
\hline
\end{tabular}

Fig 6

(C) 2019 International Federation for Medical and Biological Engineering 
AUTHOR ACCEPTED MANUSCRIPT

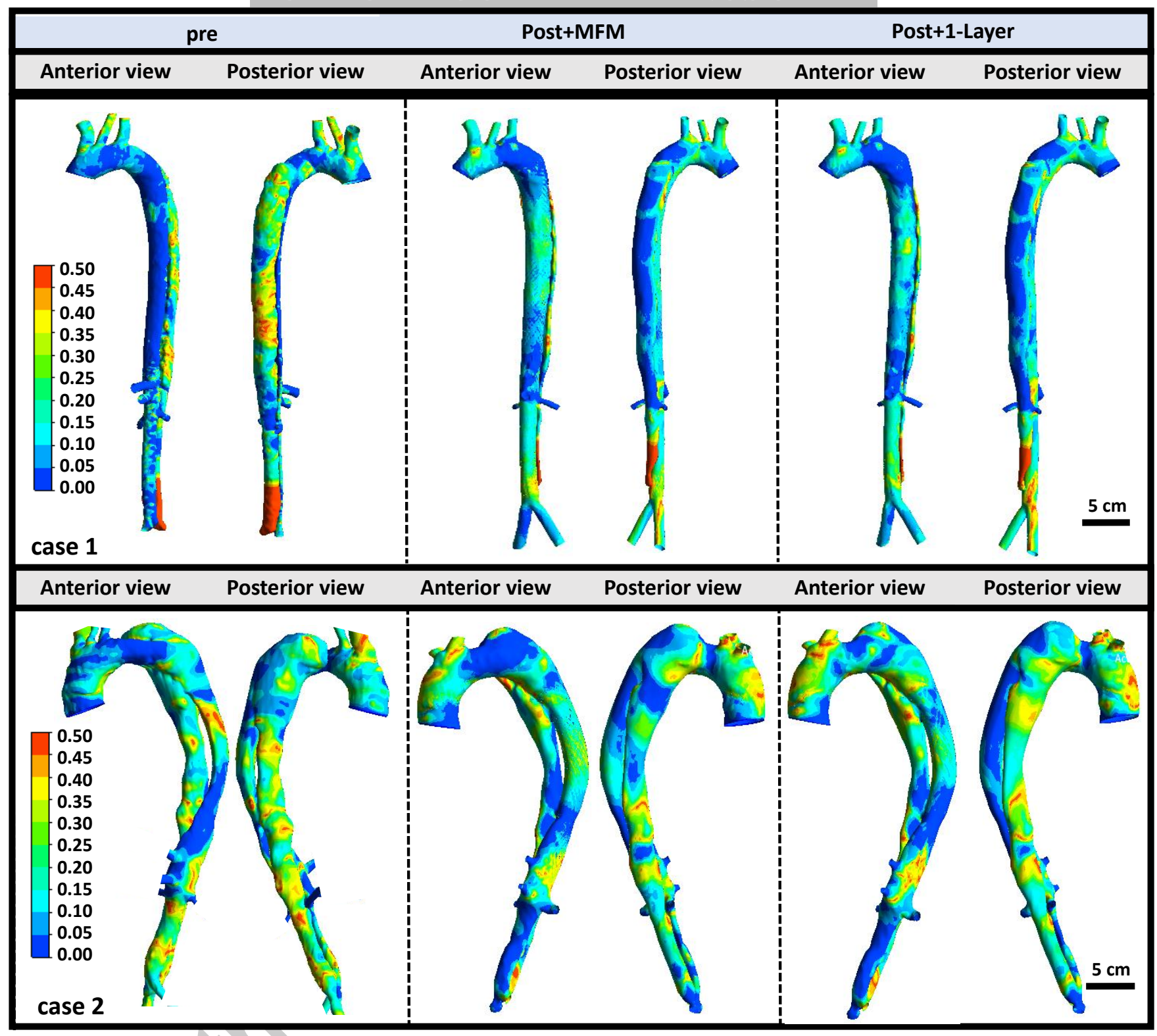

Fig 7

(C) 2019 International Federation for Medical and Biological Engineering 
AUTHOR ACCEPTED MANUSCRIPTI

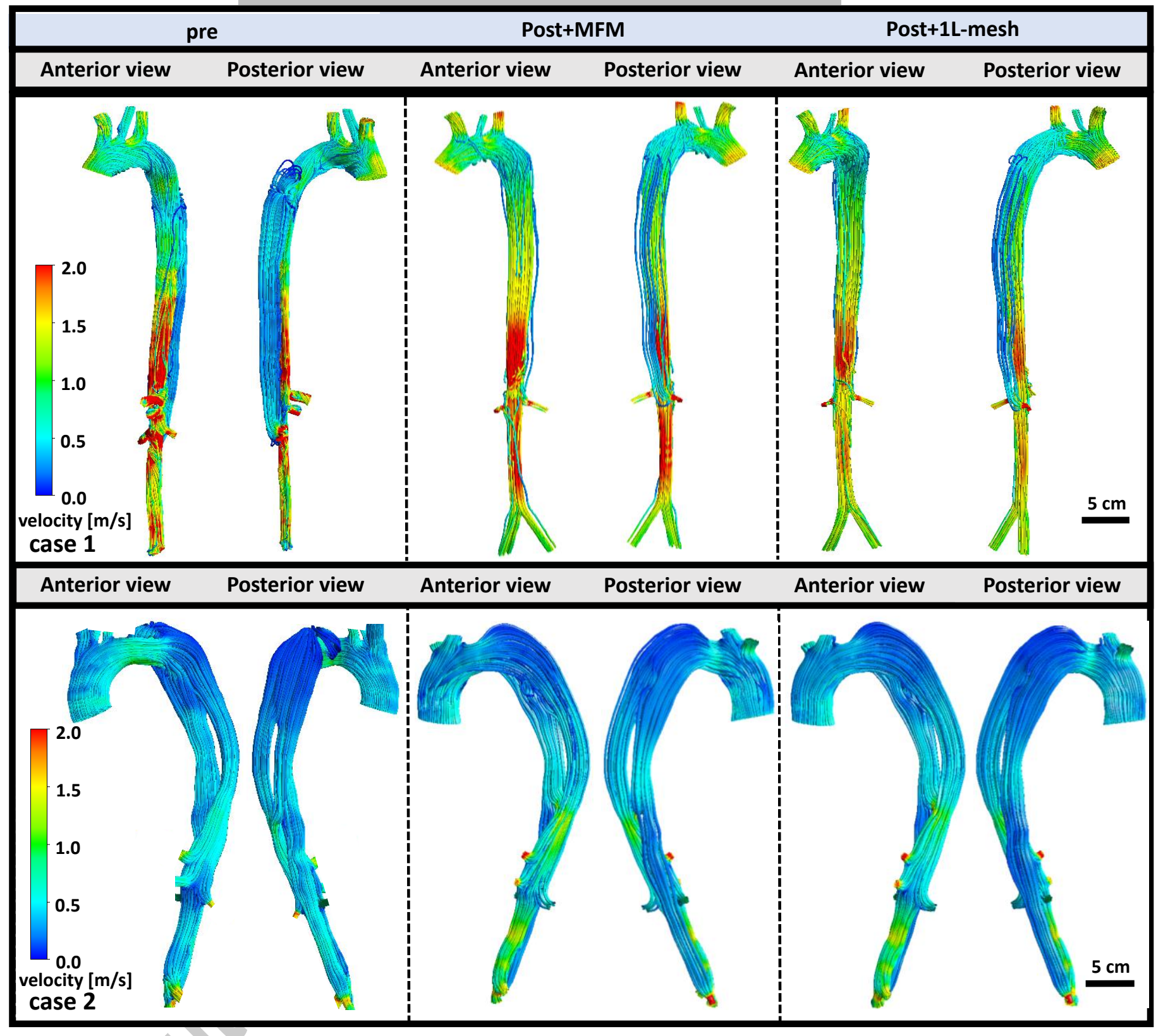

Fig 8

(C) 2019 International Federation for Medical and Biological Engineering 
AUTHOR ACCEPTED MANUSCRIPTI

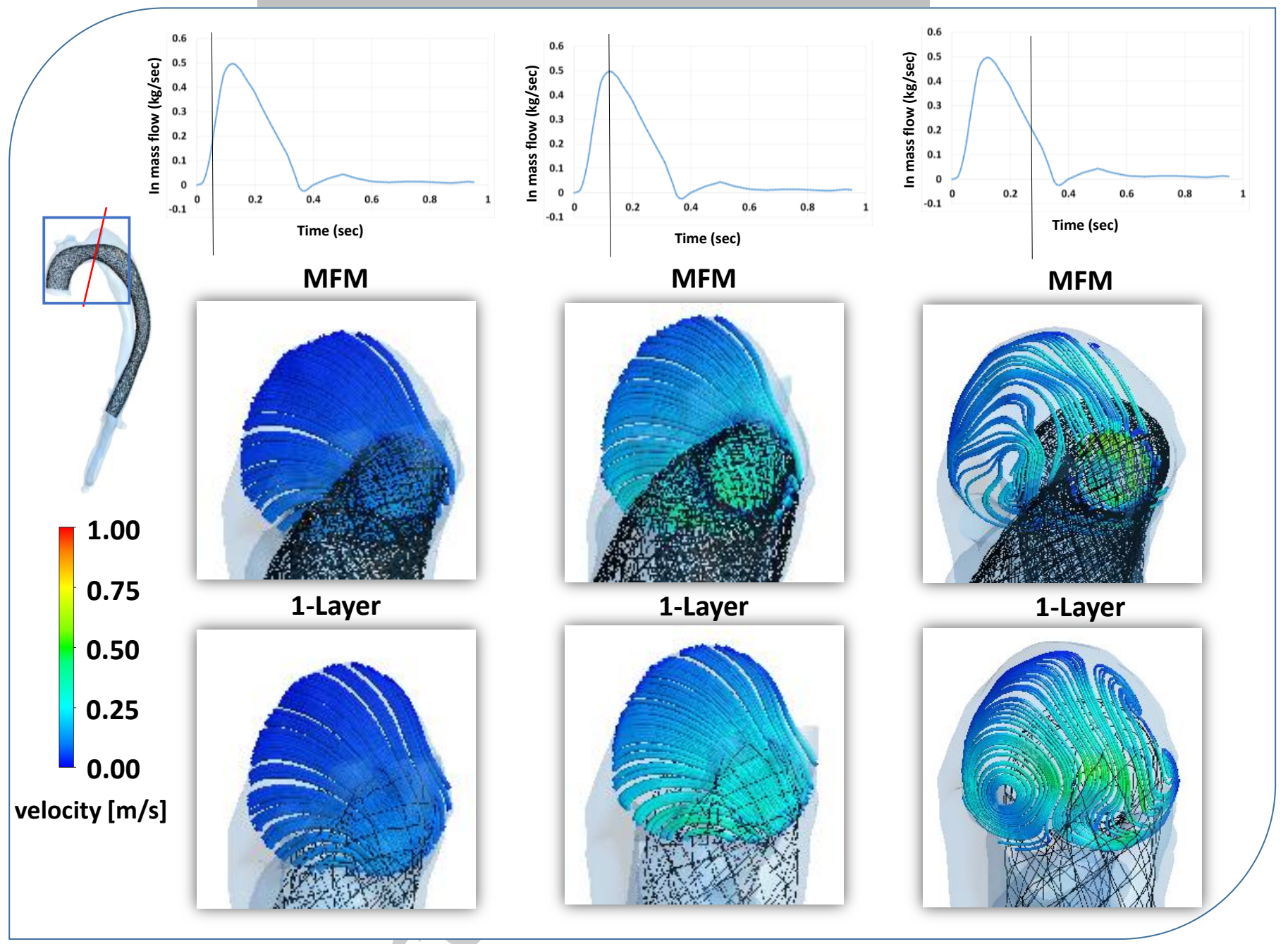

Fig 9

(C) 2019 International Federation for Medical and Biological Engineering 


\section{AUTHOR ACCEPTED MANUSCRIPTI}

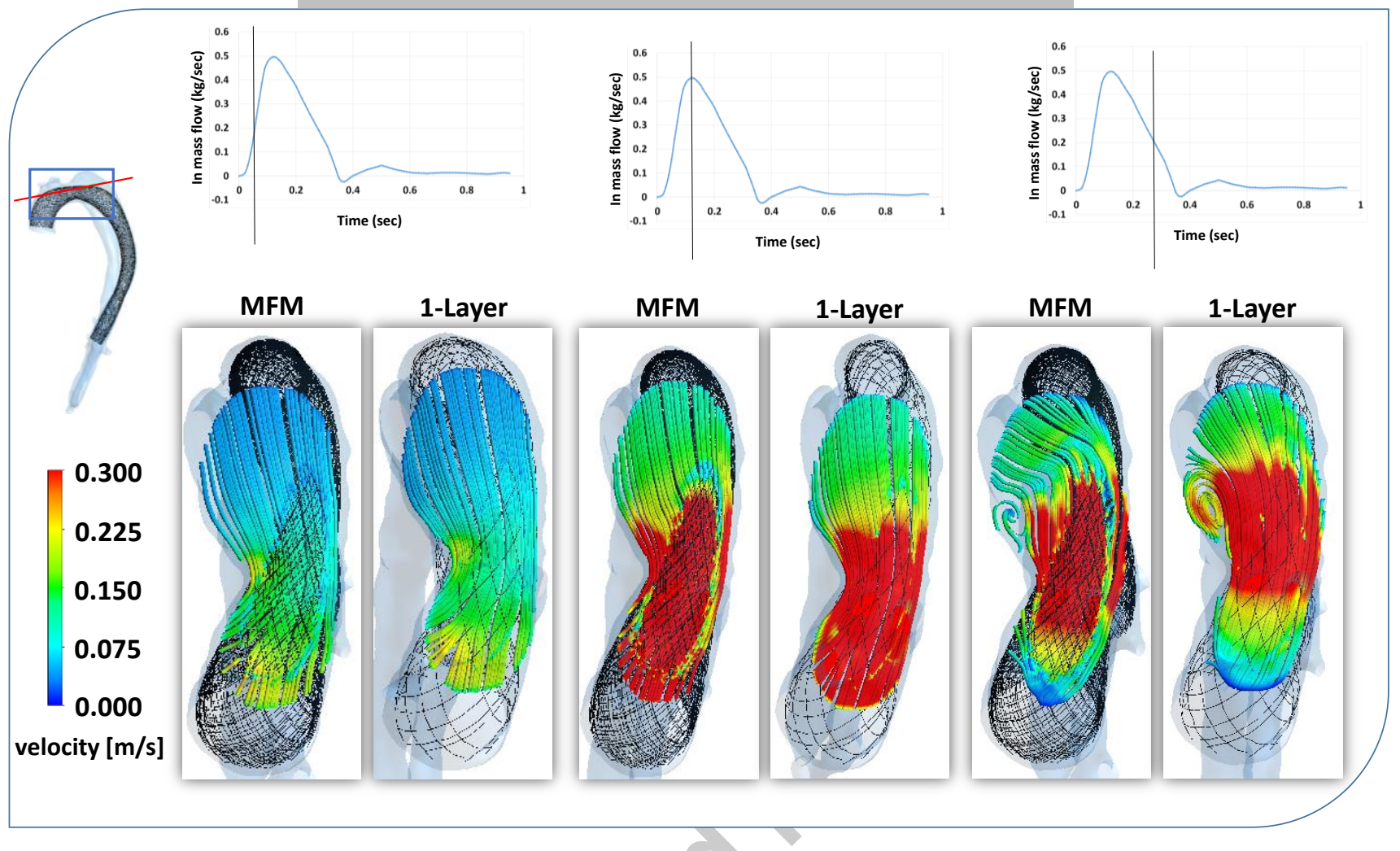

Fig 10 


\section{AUTHOR ACCEPTED MANUSCRIPT}

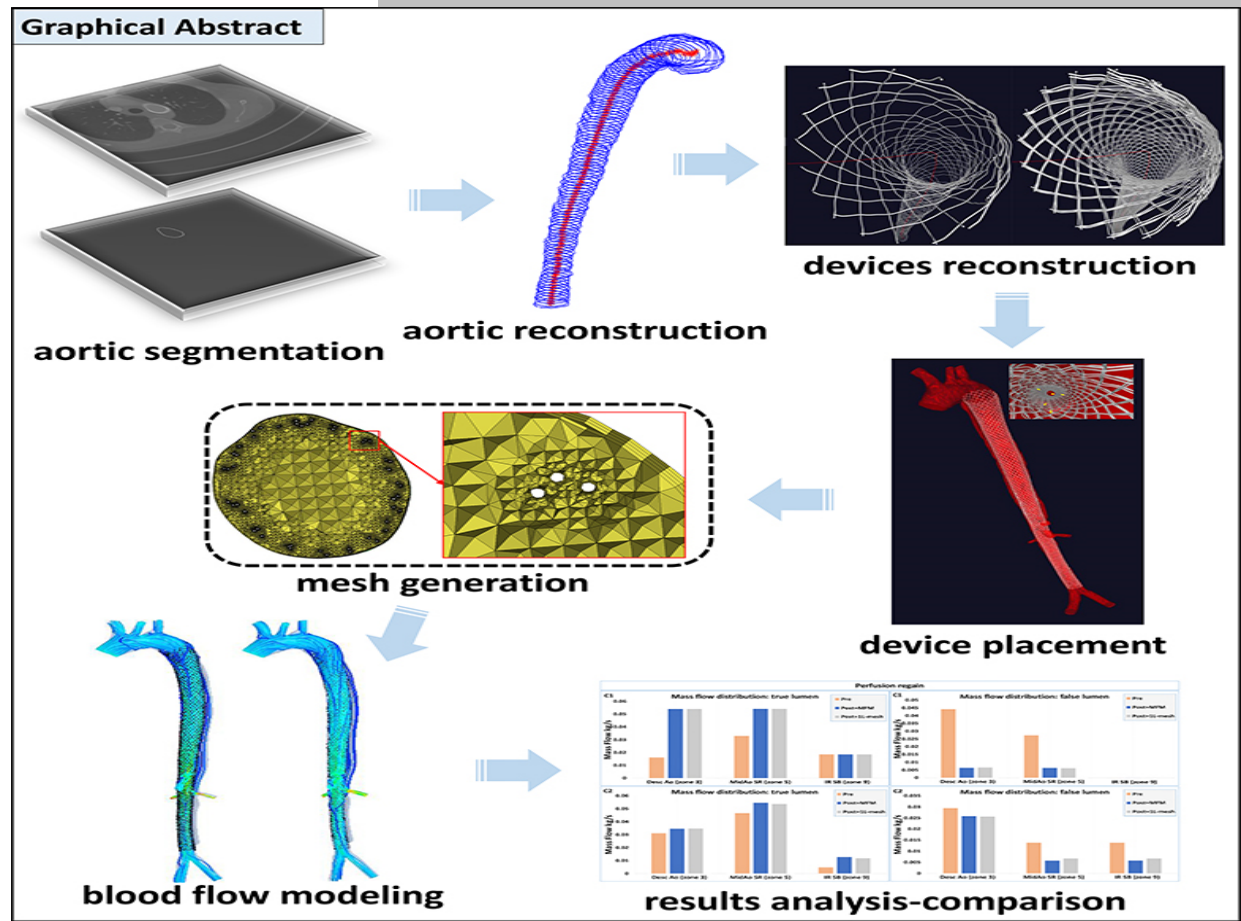

(C) 2019 International Federation for Medical and Biological Engineering 


\section{Table 1}

\section{AUTHOR ACCEPTED MANUSCRIPT}

\begin{tabular}{|c|c|c|c|c|c|c|c|}
\hline $\begin{array}{c}\text { CT } \\
\text { exam }\end{array}$ & Case \# & $\begin{array}{l}\text { Patient's } \\
\text { Gender }\end{array}$ & $\begin{array}{c}\text { Age } \\
\text { (years) }\end{array}$ & $\begin{array}{c}\text { Post- } \\
\text { surgical } \\
\text { (days) }\end{array}$ & $\begin{array}{c}\text { Location } \\
\text { of entry } \\
\text { tear }\end{array}$ & $\begin{array}{c}\text { Location } \\
\text { of re-entry } \\
\text { tear }\end{array}$ & $\begin{array}{l}\text { Location } \\
\text { of MFM }\end{array}$ \\
\hline 1 & \multirow{4}{*}{1} & \multirow{4}{*}{$\mathrm{F}$} & \multirow{4}{*}{28} & 3 & \multirow{4}{*}{ zone 4} & \multirow{4}{*}{ zones 4:9 } & \multirow{4}{*}{ zones $4: 9$} \\
\hline 2 & & & & 60 & & & \\
\hline 3 & & & & 180 & & & \\
\hline 4 & & & & 330 & & & \\
\hline 5 & \multirow{4}{*}{2} & \multirow{4}{*}{$\mathrm{M}$} & \multirow{4}{*}{48} & 3 & & & \multirow{4}{*}{ zones $0: 6$} \\
\hline 6 & & & & 90 & & & \\
\hline 7 & & & & 365 & & $3: 10$ & \\
\hline 8 & & & & 720 & & & \\
\hline
\end{tabular}




\section{AUTHOR ACCEPTED MANUSCRIPT}

Table 2

\begin{tabular}{|c|c|c|c|}
\hline$\mu_{O}[\mathrm{~Pa} \cdot \mathrm{s}]$ & $\mu_{\infty}[\mathrm{Pa} \cdot \mathrm{s}]$ & $\lambda(\mathrm{s})$ & $\mathrm{n}$ \\
\hline 0.25 & 0.0035 & 25 & 0.25 \\
\hline
\end{tabular}

